\title{
Elderly Friendly Hospital Concept First Application in Our Country: Izmir Model
}

\author{
Nurgul Kocakoc \\ Ege University, Institute of Health Sciences, \\ Internal Medicine, Geriatric Health, Izmir, Turkey \\ E-mail: nkocakoc@gmail.com \\ Sevnaz Sahin \\ Ege University, Internal Medicine, Geriatrics US, Izmir, Turkey \\ E-mail: drsevnaz@gmail.com \\ Fehmi Akcicek \\ Ege University, Internal Medicine, Geriatrics US, Izmir, Turkey \\ E-mail: fehmi.akcicek@gmail.com
}

\begin{abstract}
Care and hospital experience of elderly people in hospitals are among the important determinants of the health and well-being of older adults. A comprehensive and coordinated system should be established in order to protect their health and respond to their demands, considering that the elderly, whose population in the society is increasing day by day, is receiving service from every unit of the hospital. Older adults often have complex health and social needs due to multiple chronic medical conditions, cognitive and physical functional limitations. In addition, due to the biological factors, social and emotional isolation and the burden on caregivers, a different design is required in the health service for the elderly than the health service offered to other risky groups. Care systems are often inadequate, as current healthcare delivery systems are not sufficiently compatible with these complex needs. Dozens of different care models have been developed to improve care for older adults, but the spread and scale of these models has been limited. A first as a state hospital in Izmir in Turkey has been organized in accordance with the criteria elderly-friendly hospitals. These culturally and socially adapted criteria need to become widespread throughout the country as soon as possible.
\end{abstract}

Key Words: Elderly, Age Friendly, Health Service, Health Care, Geriatrics

\section{Special Issue of Health Sciences}

DOI: $10.7176 / J S T R / 6-03-19$

\section{Yaşıı Dostu Hastane Kavramı Ülkemizdeki İlk Uygulaması: İzmir Modeli}

Özet

Yaşlıların hastanelerde aldıkları bakım ve hastane deneyimi, yaşlı erişkinlerin sağlığı ve refahındaki önemli belirleyiciler arasındadır. Toplum içindeki popülasyonu her geçen gün artan yaşlıların hastanenin her biriminden hizmet aldıkları göz önünde bulundurularak sağlıklarını korumak ve taleplerine cevap vermek için kapsamlı ve koordine bir sistem kurulmalıdır. Yaşlı yetişkinler sıklıkla, birden fazla kronik tıbbi rahatsızlıklar, yaşadıkları bilişsel ve fiziksel fonksiyonel kısıtlamalardan dolayı karmaşı sağlık ve sosyal ihtiyaçlara sahiptir. Bunların yanı sıra biyolojik faktörler, sosyal ve duygusal izolasyon ve bakım verenlerin üzerindeki yük nedeniyle yaşlıya yönelik sağlık hizmetinde diğer riskli gruplara sunulan sağlık hizmetinden farklı bir tasarım gerekmektedir. Mevcut sağlık hizmeti sunum sistemleri bu karmaşık ihtiyaçlarla yeterince uyumlu olmadığından, bakım sistemleri genellikle yetersiz kalır. Yaşlı yetişkinlere yönelik bakımı iyileştirecek düzinelerce farklı bakım modeli geliştirilmiş, ancak bu modellerin yayılması ve ölçeği sınırlı kalmıştır. Türkiye'de bir ilk olarak İzmir'de bir devlet hastanesi yaşlı dostu hastane kriterleri doğrultusunda organize edilmiştir. Kültürel ve toplumsal olarak adapte edilen bu kritelerin bir an önce tüm ülkede yaygınlaşmasına ihtiyaç vardır.

Anahtar Kelimeler: Yaşlı, Yaş̧ı Dostu, Sağlık Sistemleri, Sağlık Bakım, Geriatri

158 | P a g e

www.iiste.org 


\section{Giriş}

1950'li yıllarda 65 yaş ve üzeri nüfusun toplum içindeki oranı \% 3,3, 2012 yılında \% 7,5 iken, 65 yaş ve üzeri nüfus 2019 yılında Türkiye'de \% 9,1'e ulaşmıştır. Bu oranın 2040 yılında \% 16,3, 2060 yılında \% 22,6, 2080 yılında ise \% 25,6 olacağı öngörülmektedir (TUİ, 2020). Bu verilerden nüfusumuzun hızla yaşlandığ 1 anlaşılmaktadır.

Uzun ömürlülüğün arttırılması sağlık ve bakım sisteminin önemli rol oynadığı büyük bir başarı öyküsüdür. Doğuşta beklenen yaşam süresinin uzaması aynı zamanda toplumdaki sağlık ve bakım ihtiyaçlarını değiştirmede de önemli bir faktördür. TÜİK tarafından yayımlanan Hayat Tabloları, 20162018'e göre ülkemizde (TUİK Bülteni, 2019);

- Doğuşta beklenen yaşam süresi 78,3 yıl (erkeklerde 75,6 yıl, kadınlarda 81 yıl),

- Doğuşta beklenen sağlıklı yaşam süresi ise 58,3 yıl olmuştur.

$\mathrm{Bu}$ veriler yaşlı bireylerin yaşamlarının ortalama 20 yılını kronik hastalıklarla birlikte geçireceği, sağlık hizmetine daha çok ihtiyaç duyacağı şeklinde yorumlanabilir. Nitekim batı ülkelerinde yapılan çalışmalarda yaşlı nüfus toplam nüfusun \%15'ini oluştururken, \%15'lik bu kesim hastaneye kabullerin \% 50'den fazlasını oluşturmakta ve sağlık kaynaklarının yaklaşık \% 40'ını tüketmektedir (TSYEPUP, 2015). Artan yaşlı nüfusun genel olarak sağlık ve bakım hizmetlerine olan talebi arttıracağı aşikardır. Sağlık sistemi daha karmaşık ihtiyaçları olan çok sayıda insana hizmet eder hale gelecek, bu da hizmetleri yeniden tasarlama, sistemleri modernize etme ve sağlık iş gücü planlaması ile ilgili düzenleme yapılması ihtiyacını doğuracaktır. Dünyada yaşlı yetişkinlere yönelik bakımı iyileştirecek düzinelerce farklı bakım modeli geliştirilmiş, ancak bu modellerin yayılması ve ölçeği sınırlı kalmıştır (Mate KS. et al.,2018). Yaşlı yetişkinlerin karmaşık ve birbiriyle ilişkili ihtiyaçlarını ele almak için güvenli, daha etkin ve hasta odaklı, potansiyel sağlık gereksinimlerini ele alan, önlenebilir zararları önleyen ve komplike ihtiyaçlarına yönelik bakımı iyileştiren proaktif modeller gereklidir (Fulmer T. et al, 2018). Yaşlı nüfus arttıkça mevcut sağlık sisteminde bir değişiklik yapılmadığı taktirde; ihtiyaç duyulan hizmetlere erişimin sınırlı olacağı, yaşlı yetişkinler tarafından alınan bakımın kalitesinin kötüleşeceği ve sistemin mali sıkıntı yaşayacağı aşikardır (Fulmer T., \& Berman A., 2019).

Ülkemizde sağlık hizmeti birinci, ikinci ve üçüncü basamak sağlık hizmetleri olarak basamaklandırılmış bir modelde sunulmaktadır. Sağlık hizmeti öznesi insan olan bir hizmet olması nedeniyle sürdürülebilirliği ve devamlılığı şart olup, basamaklar arası iletişim ve işbirliği sunulan hizmetin etkinliği ve kalitesi açısından son derece önemlidir. Nitekim 2015 yılında Sağlık Bakanlı̆̆ tarafindan yayımlanmış olan Türkiye Sağlıklı Yaşlanma Eylem Planı ve Uygulama Programında (TSYEPUP, 2015) "yaşlı dostu merkez kavramının birinci, ikinci ve üçüncü basamakta oluşturulması" yaşlı bireyler için sağlık hizmetlerinin geliştirilmesi hedefinin gerçekleştirilecek etkinliği olarak tanımlanmıştır. Bu nedenle ülkemizde yaşlı dostu sağlık kurumları üzerine çalışmalara hastane düzenlemelerinin yanı sıra birinci basamak hizmetlerde de hız verilmelidir. Yaşlı dostu girişimin amacı, yataklı, ayaktan, akut bakım sonrası ve evde bakım gibi tüm bakım ortamlarında yaşlı yetişkinlere yönelik bakımı iyileştirmektir (Mate KS. et al.,2018). Dünya Sağlık Örgütü (DSÖ, WHO) tarafından "yaşlıların özel ihtiyaçlarına yönelik dizayn edilmiş, güvenli, bütüncül yaklaşım ve saygı ile hizmet veren, hem yaşlıyı hem de ailesini sağlığ 1 geliştirme yönünde bilgilendiren bir hastane" olarak yapılan Yaşı Dostu Hastane tanımında da bütüncül bakıma yapılan vurgu dikkat çekicidir (WHO, 2019).

Özellikle sağlıkları konusunda özerklik ve karar alma süreçlerine katılım isteyen yaşlı hastalar, yaşa bağlı değişik derecelerde fizyolojik değişim, hastalık, fonksiyonel kapasite ve yeteneklerde düşüş yaşayan heterojen bir gruptur. Yaşlı hastalar çoğunlukla fonksiyonel olarak bağımsız, bilişsel olarak farkında ve öz bakımını sağlayabilir durumdadır. Mevcut literatür bazı yaşlı hastaların geleneksel akut bakım modeline uygun olmayan ihtiyaçlara sahip olduklarını göstermektedir. Geleneksel hastane bakımı akut olarak ortaya çıkan patolojiye odaklanmıştır. Bununla birlikte, yaşlı yetişkinler, karmaşık sağlık problemleri, kaygıları ve sosyal durumları ile birlikte hastaneye gelmektedir. $\mathrm{Bu}$ nedenle bu popülasyonun tüm benzersiz ihtiyaçlarını içerecek şekilde geleneksel değerlendirme ve tedavi planının ötesine geçmek gereklidir (Parke B.,\& Stevenson L., 1999). Bireysel ve çevresel faktörlerin kombinasyonu, yaşadıkları görsel, işitsel, fiziksel, kas-iskelet veya bilişsel değişiklikler bu grubun işlev görme, stresle baş etme ve hastane ortamındaki baskılara uyma yeteneğini etkilemektedir. Bu nedenle hastanedeyken durumları için makul olduğu düşünülen süreden daha fazla zaman alan sağlık ihtiyaçları vardır; sosyal destekleri azdır, kısmen daha çaresizdirler, işbirliği ve prosedürlere uyum konusunda sorun yaşar ve özel ilgi isterler. Bu hastaların ihtiyaçları ile hastanelerde akut bakıma yanıt veren hızla işleyen yapılanma arasındaki uyumsuzluk, hastane çalışanlarının yaşlı hastalara karşı iş ve görevlerini yerine getirmesini de zorlaştırmaktadır (Parke B., 2007). 


\section{Yaşı Dostu Sağlık Kurumları Yaklaşımı}

Bireyin alıştığı ortamda, aktif ve sağlıklı yaşlanması için yaşlıya sunulacak sağlık hizmetlerinin modellenmesi şarttır. Genel olarak dünyadaki uygulama örneklerine bakıldığında, asgari engellilik standartlarının yaşlıların spesifik fiziksel çevre ihtiyaçlarını tam olarak karşılamıyor olması gerekçesi ile engelsiz erişilebilirlik asgari standartlarına ek olarak hastanelerin yaşlı yetişkinlerin ihtiyaçlarını karşılayacak fiziksel bir ortam yaratmalarına yardımcı olacak kılavuzlar geliştirildiği görülmektedir (Parke B., \& Friesen K., 2015; WHO, 2008).

Nitekim 2004 yılında Dünya Sağlık Örgütü (DSÖ) yaşlı dostu sağlık bakımının şartlarını oluşturmak üzere Aktif Yaşlanma: Yaşlı Dostu Temel Sağllk Bakımına Doğru (Active Ageing: Towards Age Friendly Primary Health Care) Rehberini hazırlamıştır. 2008 y1lında da Yaşlı Dostu Temel Sağllk Bakımı Merkezleri Araç Kitini (Age Friendly Primary Health Care Centres Toolkit, Age-Friendly Primary Health Care Centres Toolkit Trainer Guide for Normal Ageing and Communication) oluşturmuştur. DSÖ tarafindan hazırlanan rehberlerin amacı (Age Friendly, 2008);

- Sağlık çalışanlarını yaşlıların özel ihtiyaçları konusunda duyarlı hale getirmek ve eğitmek,

- Yaşlilara yönelik sunulan sağllk hizmetini iyileştirmek,

- Yaşlıların engellerine yönelik bilinçlenme ve farkındalık yaratmak,

- Geriatrik bakım araçlarının kullanım ve uygulanmasını desteklemek,

- Sağlık bakımı ve yönetimi prosedürlerinin yaşlı bireylerin ihtiyaçlarına daha fazla cevap vermesi için rehberlik etmek,

- Sağlık kurumlarının yaşlı dostu olmaları için ortam denetimleri konusunda rehberlik etmek şeklinde sayılabilir.

DSÖ sağlık kurumlarında yaşlı dostu uygulamasının üç prensip üzerine kurulmasını öngörmektedir;

1) Bilgilendirme (eğitim, öğretim, iletişim),

2) Sağllk bakım yönetim sistemleri,

3) Sağlık bakım merkezlerinin fiziksel ortamı.

\section{Yaşıı Dostu Hastane}

Bu konudaki en önemli çalışmalar Kanada'da yapılmıştır. Kanada'nın Toronto Eyaletinde bu alanda yapılan uygulamalarda yaşlı dostu hastanede strateji organizasyonel destek, bakım süreci, duygusal ve davranışsal çevre, klinik bakım ve araştırma etiği ve fiziksel çevre olmak üzere beş başlıkta toplanmıştır (Wong K. et al., 2010). Victoria, British Columbia Kanada'da bir grup üst düzey klinisyen, yönetici, gerontoloji uzmanı ve hastane hizmet profesyonelleri ile Yaşlı Dostu Hastanenin nasıl olacağını belirlemek üzere gerçekleştirilen bir vizyon çalışması sonucunda yol gösterici ilkeler belirlenmiştir (Parke B.,\& Stevenson L., 1999). Bunlar;

- Bakımın her aşamasında aile katılımı,

- Yaşlı yetişkinlerin, aileleri ve sosyal durumlarının düzenli ve devamlı disiplinler arası değerlendirilmesi,

- Geriatrik yaklaşım ile hastane tanı ve bakım yaklaşımlarının kombine edildiği bütüncül yaklaşım,

- Yaşam boyu yaklaşımı ve gelişimsel ihtiyaçların tanınması,

- Önlenebilir, geri döndürülebilir, desteklenebilir ve hafifletilebilir risk faktörleri ve problemlerin erken tanımlanması,

- Yaşlı yetişkinlerin hastanede aldıkları hizmetler için seçim yapma hakkına saygı duymak,

- Yaşlı yetişkinlerin yeteneklerini destekleyen bir ortamın yaratılması ve hastaneden taburculuk sonrasında kendilerine ve ailelerine yardım etmek için uzman ve bilgili personel ihtiyacı konusunda farkındalık, şeklinde sıralanmıştır.

Kelley ve arkadaşları tarafindan yapılan çalışmada ise yeni bir konsept olan Yaşlı Dostu Hastanelerin özellikleri çeşitli şekillerde tanımlanmış olsa da esasen fiziksel çevre, sosyal iklim, hastane politika ve prosedürleri ile sağlı sistemi sorunları şeklinde sayılabilecek dört etkileşimli boyutu olduğu ve bu unsurların kııılgan yaşlıların durumlarını da etkilediği belirtilmiştir (Kelley ML. et al., 2011). Yapılan çalışmalarda yaşlı yetişkinlerin sıklıkla üç genel alanla ilişkili sorun, endişe ve şikayet rapor etmekte olduğu, bunların bakım süreçleri, iletişim ve hastanenin fiziksel ortamı şeklinde sıralandığı, bu nedenle yaşlı dostu hastane uygulamalarına ilişkin yapılan düzenlemelerde bu konuların ana işlem basamaklarını oluşturduğu vurgulanmıştır (Parke B., 2007).

2015 yılında John A. Hartford Vakfı tarafindan Amerika Birleşik Devletleri (ABD)' nde Yaşlı Dostu Sağ lık Sistemleri Yaratma girişimi oluşturulmuş ve amaç olarak 2020 yllına kadar ABD hastane ve sağlık sistemlerinin \% 20'sinde yaşlı dostu bakım yaklaşımını yerleştirmek, belirlenmiştir. 
$\mathrm{Bu}$ modellemede sağlık sistemlerinin yaşlı bireylere mümkün olan en iyi bakımı sağlayabilmek için ihtiyaç duydukları dört temel unsur (4M) belirlenmiştir. 4M Model olarak ifade edilen bu sistemin unsurları şöyledir (What, 2019);

- Önemli olanlar (what matters),

- Mobilite (Mobility),

- İlaç tedavisi (Medication),

- Mental aktivite (Mentation).

DSÖ’nün 2012 raporunda 2050 yılında yaşlı nüfus oranının \%25'lere ulaşması beklenen İran'da 26 hastanede yapılan yaşlılara yönelik sağlık hizmeti durum tespiti çalışmasında sunulan hizmetlerde yaşlılara spesifik düzenlemeler yapılmadığı ancak İran sağlık sisteminin önemli bir politikası olan genel hastanelerde bir yaşlı bakım departmanı kurulmasının yaşlı dostu hastaneler için zemin oluşturabileceği ifade edilmiştir (Ahmadi, A. et al., 2015). Hong Kong'da yaşlı hastalar için rehabilitatif bileşenlere ek olarak kapsamlı geriatrik değerlendirme, araştırma, terapötik tedavilerin denenmesi ve tedavi etkilerinin izlenebileceği hayati işleve sahip bir kurum olarak hastane içinde konumlandırılmış gündüz hastaneleri bulunmaktadır (Woo J., 2007).

\section{3. Ülkemizde Yaşlı Dostu Hastane Uygulaması: İzmir Modeli}

Yaşlı dostu hastane programı, hastanenin her hizmetini kapsayan bir kurum kültürüne dönüşecek evrimsel bir süreçtir (Parke B.,\& Stevenson L., 1999). Ülkemizde mevcut hastaneler daha ziyade genç nüfusun hızlı bir şekilde tanı alarak, genelde tek veya akut hastalığının tıbbi veya cerrahi olarak tedavisini yapmaya yönelik kurgulanmıştır. Artık hastaneler her geçen gün artan 65 yaş ve üzeri yaşlı bireylerin hizmet alımını kolaylaştıracak tarzda dizayn edilmek zorundadır. Dünya örneklerindeki uygulamalar geriatri dal hastanelerinin kurulması, mevcut hastanelerin veya hastanenin acil servis gibi bazı bölümlerinin yaşı dostu olarak düzenlenmesi şeklindedir. Ülkemizde başta mevcut Geriatri Uzmanı hekim sayısı ve yaşlı sağlığı konusunda eğitimli sağlık meslek profesyoneli kapasitesi göz önünde bulundurulduğunda Geriatri Dal Hastanelerinin kurulması ve ülke çapında yaygınlaştırılması çok mümkün gözükmemektedir. $\mathrm{Bu}$ nedenle 2 ve 3 . Basamak Hastanelerin Yaşlı Dostu olarak düzenlenmesine yönelik çalışmalar yapılmalıdır.

2015 yılında Sağlık Bakanlığı tarafindan yayımlanmış olan Türkiye Sağlıklı Yaşlanma Eylem Planı ve Uygulama Programında (TSYEPUP, 2015) yer alan yaşlı bireyler için sağlık hizmetlerinin geliştirilmesi hedefinin gerçekleştirilmesine ilişkin etkinlikler arasında "yaşlı dostu merkez kavramının birinci, ikinci ve üçüncü basamakta oluşturulması" sayılmıştır. Bu husus bizim "Yaşlı Dostu Hastane” çalışmamızın çıkış noktasını teşkil emektedir.

İzmir modelinde amaç: yaşlılığın bir hastalık değil, yaşamın bir dönemi olduğu yaklaşımıyla 65 yaş ve üzeri bireylerin aktif, sağlıklı ve alıştığı mekanda yaşlanması için sağlık desteği sunmak ve 2 . ve 3 . basamak sağlık kurumlarına başvuran 65 yaş ve üzeri bireylere sunulacak sağlık hizmetlerini düzenlemektir. Ülkemiz Yaşlı Dostu Hastane sistemine model teşkil etmek üzere çalışmalara 2015 yılında başlanmıştır. Ege Üniversitesi Geriatri Bilim Dalı ve İzmir İl Sağlık Müdürlüğü işbirliğinde ${ }^{1}$ yürütülen çalışmalar için ilk toplantı 03.12.2015 tarihinde gerçekleştirilmiş, toplantılar periyodik olarak devam etmiştir. Dokuz Eylül Üniversitesi Fizik Tedavi ve Rehabilitasyon Yüksekokulu ve Akdeniz Üniversitesi Gerontoloji Bilim Dalı projemize destek vermiştir. Proje beş aşamadan oluşmaktadır. Bunlar:

1. Yaşlı dostu hastane kurum kültürü oluşturmak,

2. Fiziksel düzenlemeler,

3. Eğitim,

a. Sağlık çalışanlarını yaşlı hastaların sorunları hakkında duyarlı kılmak amacıyla eğitim (sistemin sürekliliği açısından bu alanda yetkin eğiticiler yetiştirmek),

b. Hasta ve hasta yakınlarının eğitimi (broşürler, afişler, fiziksel aktivite danışmanlığı, kullanılan medikal aparatlara yönelik eğitim vs.),

4. Sistemi standardize etmek amaciyla kriterler oluşturmak,

5. Sistemi periyodik olarak değerlendirmek, olarak belirlenmiştir.

Projenin nihai hedefi ülkemizdeki tüm hastanelerde sistemin kurulması ve yaşlı dostu hastane uygulamasının Ulusal düzeyde yaygınlaştırılmasıdır. Bu amaçla içinde tüm sağlık disiplinlerinden üyelerin yer aldığ 1 bir çalışma komitesi oluşturulmuştur. 2016 yılı içinde komite tarafindan yaşlı hastalar

\footnotetext{
${ }^{1} 2015$ yılında çalışmalar İzmir Kamu Hastaneleri Birliği Güney Genel Sekreterliği bünyesinde başlamış, 02.10.2017 tarih 2017/17 sayılı Taşra Teşkilatı Genelgesi ile sağlık kurumlarının tek çatına altında toplanması neticesinde proje İl Sağlık Müdürlüğü bünyesinde devam etmiştir.
}

$161 \mid \mathrm{P}$ a g e

www.iiste.org 
ve bakım sağlayıcılara yönelik broşürler ve eğitim materyalleri hazırlanmıştır. Çalışanların yaşlı bireyi fizyolojik, sosyolojik ve biyolojik açıdan tanıma, yaşı ı hastaya yaklaşım ve etkin iletişim konularında farkındalık eğitimleri planlanmıştır. Etkin ve kapsamlı eğitim materyallerinin hazırlanması için bir çalıştay yapılmasına karar verilmiştir. Proje uygulama hastanesi olarak İzmir Urla Devlet Hastanesi belirlenmiş ve proje ekibi tarafından birçok kereler hastaneye ziyaret gerçekleştirilmiştir. Urla Devlet Hastanesi proje hastanesi olarak belirlenirken ilçe 65 yaş ve üzeri nüfusunun \%16,5 ( 2016 yılı \%14,94, 2017 yılı \%15,33, 2018 yılı için \%16) olması, hastanede 2. Düzey Genel Yoğun Bakım Ünitesi, Palyatif Bakım Birimi ve 2. Düzey Acil Servis bulunması, hastanenin 2014 yılında hizmete girmiş olması ve kurumun bu çalışmada gönüllü olması etkili olmuştur.

Ülkemiz "Yaşlı Dostu Hastane" modelini belirlemek için 11.05.2016 tarihinde, bu alanda çalışmakta olan meslek profesyonellerinin bir araya getirildiği "Yaşlı Dostu Sağlık Kurumları Çalıştayı" gerçekleştirilmiş, kurulacak sistem ile ilgili görüş ve önerilerinin alınması yanı sıra bu alandaki bilgi birikimleri ve deneyimlerinden faydalanılmıştır. Çalıştayda; Yaşlı Dostu Hastane Kavramı, Yaşlı Dostu Hastane Kavramına Mekansal Yaklaşım, Yaşlı Dostu Hastane Kavramına Mesleki Yaklaşım konuları ele alınmıştır. Multidisipliner bir yaklaşımla çalıştaya Hekim, Gerontolog, Psikolog, Eczacı, Sosyal Hizmet Uzmanı, Diyetisyen, Hemşire, Mimar, Fizyoterapist meslek dallarından 76 kişi katılım ve katkı sağlamıştır. Yaşı Dostu Hastane unvanını alan hastanelerde kullanılmak üzere yapılan logo çalışmaları çalıştay katılımcılarına sunulmuş ve hazırlanan taslaklar arasından ${ }^{2}$, yaşlılıkta bilgeliği, sağlıklı ve aktif yaşlanmayı temsilen istiridye kabuğu içinde inci tanesi oy birliği ile yaşlı dostu sağlık kurumları için logo olarak kabul edilmiştir.

\subsection{Eğitim Üzerine Çalışmalar}

Hastanenin tüm birimlerinde çalışan personelin yaşlı dostu bakım konusunda eğitilmesi üst düzey bir duygusal ve davranışsal ortamın geliştirilmesine yardımcı olur. Nitekim Hartford Üniversitesi'nde uygulanan Yaşlı Sağlığında Bakımın Geliştirilmesi Sistemi (NICHE) programında çok katmanlı bir eğitim programı tanımlanmış olup, bu modelde klinik dışı personel yaşlı yetişkinlerin personel-hasta etkileşimlerindeki ihtiyaçları konusunda farkındalıklarını arttırmak için eğitilmiştir. Tüm klinik personeli de yaşlılık ile ilgili fizyolojik değişimler ve hastanede yatış tehlikeleri konusunda eğitilirken, daha az sayıda klinik personel geriatrik klinik liderleri yetiştirmek için daha kapsamlı bir müfredatla donatılmaktadır. Programın ayrıca yaşlılarla etkileşime giren hastane gönüllüleri için de bir eğitim bileşeni bulunmaktadır (Wong K. et al., 2010). Woo ve arkadaşları tarafından yaşlı dostu sağlık sistemlerine yönelik hazırlanmış olan rehberde yer alan üç işlem başlığından birisi bilgi, eğitim ve öğretimdir (Woo J. et al., 2013). Dünyadaki yaşlı dostu hastane çalışmalarının tümünde çalışanların yaşlı bireylere yönelik eğitimleri yer almaktadır. Bu projenin nihai hedefi "yaşlı dostu hastane" uygulamasının Ulusal bazda yaygınlaştırılmasıdır. Bu yaygınlaştırmada sağlık hizmeti sunumunun her aşamasında görev yapan tüm meslek profesyonellerinin yaşı hastaya yaklaşım, etkin ve doğru iletişim, hastalıkları ve fizyolojisi hakkında farkındalık konusunda yeterli bilgi ve eğitime sahip olması ve uygulamayı yapacak tüm hastanelerdeki çalışanların aynı eğitimi alması uygulama birliği açısından son derece önemlidir. İşte bu öngörüyle 01.06.2017 tarihinde "Yaşl1 Dostu Hastane Eğitimlerinin Hazırlanması ve Standardizasyonu Çalıştayı" gerçekleştirilmiştir. Çalıştay sonunda "Yaşlı Dostu Hastane” uygulaması ve düzenlemesi yapacak hastanelerimizde hizmet veren personelin eğitimi için kullanılacak dokümanlar oluşturulmuş, eğitimin etkinliğini ölçmek amacıyla ön/son test soruları hazırlanmıştır. Çalışmalar neticesinde sekiz ana başlık altında yirmi dört alt başlıkta çalışma yapılmış ve on altı saatlik eğitim materyali hazırlanmıştır. Sonrasında İzmir il ve ilçelerinde Hekim, Hemşire, Psikolog, Fizyoterapist ve Hastane Yöneticilerinden oluşan gruplara eğitici eğitimi verilmiştir.

\subsection{Yaşlı Dostu Hastane Kriterleri}

Kriterlerin hazırlanmasında DSÖ Rehberleri, Kanada Code Plus: Physical Design Components for an Elder Friendly Hospital. The 2nd Edition, Kanada Prens Edward Adası Sağlık Otoritesi tarafindan hazırlanmış olan Health PEI Senior Friendly Medical Unit Rehberi, Kanada A Summary of Senior Friendly Care in Toronto Central LHIN Hospitals Rehberi, Background Document: Senior Friendly Care in Hamilton Niagara Haldimand Brant LHIN Hospitals Dokümanı, Sağlık Bakanlığ1 Sağlık Kurumlarında Engelli Bireyler İçin Ulaşılabilirlik Temel Bilgiler Rehberi ve Mimarlar Odası Ulaşılabilirlik Kılavuzundan faydalanılmıştır. Kriterler genel düzenlemeler, hastane içi düzenlemeler ve eğitim olarak üç ana başlıkta toplanmıştır (Ek 1).

${ }^{2}$ Logo çalışmaları Grafik Tasarımcısı Recep ÖNAL tarafindan yapılmıştır.

162 | P a g e

www.iiste.org 
1. Genel Düzenlemeler; 18 kriter,

2. Hastane İçi Düzenlemeler;

- Koridor ve Hastane Girişleri; 17 kriter,

- Asansör ve Merdivenler; 9 kriter,

- Kapilar; 5 kriter,

- Tuvalet ve Banyolar; 7 kriter,

- Yönlendirme Levhaları ve Bilgilendirme; 8 kriter,

- Klinikler; 7 kriter,

3. Eğitim;

- Yaşlı ve Yakınlarının Eğitimi; 13 kriter,

- Personel Eğitimi; 30 kriter,

- Genel; 1 kriter, olmak üzere toplamda 115 kriter oluşturulmuştur.

Hastanelerin yaşlı dostu olarak yapılandırılması çalışmalarının hemen tümünde fiziksel çevrenin düzenlenmesine yer verilmiştir. Yaşlılara sunulan bakım hizmetinin önündeki engel olarak en sık fiziksel çevre rapor edilmiştir. Fiziksel tesisin elemanlarının geliştirilmesi, satın alınması ve muhafaza edilmesi, eğitime katılan ekiplerin yaşlı dostu tasarım hakkında bilgilendirilmesinin sağlanması, yaşlıların ve diğer kırılgan grupların ihtiyaçlarını karşılayan fiziksel bir çevrenin gelişimini teşvik edecektir (Wong K. et al., 2010).

Fiziksel çevre yaşlıların bağımsız fonksiyonel kapasitesini maksimum düzeyde destekler nitelikte ve evrensel tasarım ilkelerine uygun olmalıdır. Bu açıdan fiziksel çevrede; renk, ışıklandırma, yön bulma, koridor, işitsel uyaranlar, dış mekan düzenlemeleri (otopark, yürüyüş yolları), iç mekan düzenlemeleri (mobilya, donanım) son derece önemli olup, fiziksel mekanın performansı optimize edilerek, kaza riski en aza indirilmeli, böylece yaşıının fonksiyonel kapasitesi korunabilmelidir. Gerontolojik ilkelere göre fiziksel mekanlarda yaşlı yetişkinler için güvenli, otonomilerine saygılı, günlük yaşam faaliyetlerinde bağımsız oldukları ve sorun çözme odaklı bir ortam oluşturulmalıdır (Parke B., 2007). Nitekim çalışmamızda "hastane içi düzenlemeler" ana başlığı altında fiziksel düzenlemelere ilişkin kriterler oluşturulmuştur. Kriterler hastanenin tüm bölümlerini ( servisler, asansör, merdiven ve koridorlar, tuvalet, banyo, kapılar, yönlendirme tabelaları vb.) kapsayacak şekildedir. Belirlenen kriterlerin evrensel tasarım ilkeleri ve engelli bireyler için ulaşılabilirlik kriterleriyle uyumlu olmasına dikkat edilmiştir. Acil Servis ortamlarının yaşlıların fiziksel ve zihinsel sağlı̆̆ üzerindeki olumsuz etkileri, hastanelerde oluşan önlenebilir yan etkilerin sıklığı, yaşlılar için acildeki yatak bekleme sürelerinin uzunluğu politika değişikliklerine duyulan gereksinimleri işaret etmektedir. Yapılan odak grup çalışmalarında sağlık çalışanları yaşlıların acil serviste mahremiyete saygılı, konforlu ve kalite odaklı hizmet almaları gerektiğini vurgulamaktadır (Kelley ML. et al., 2011). Bu nedenle Urla Devlet Hastanesi'nde acil servis içerisinde 65 yaş ve üzeri hastaların muayenesi için özel bir alan ve müşahede bölümü oluşturulmuştur.

\subsection{Kurum Politika ve Taahhütleri}

Yaşlı dostu sağlık hizmetinin sunumunda sistemin tanımlanması, kapsamı ve kurumun konuya ilişkin politika ve taahhütlerini belirleyerek ilan etmesi sistemin çalışanlarca da benimsenmesi ve uygulanması üzerine son derece etkilidir. Kurum yaşlı ayrımcılığı, istismarı ve ihmaline karşı mücadeleyi taahhüt etmeli, bakım veren aile üyelerini koordine etme ve destekleme konusunda çalışmalar yapmalı, bakımın kurumlararası koordinasyonunu sağlayabilmelidir (Fulmer T., \& Berman A., 2019). İşte bu nedenle “Yaşlı Dostu Hastane Politikası” nın hastaların görebileceği alanlarda ilan edilmesine kriterler arasında yer verilmiştir (Ek 2).

\section{Tartışma ve Sonuç}

Mevcut hastaneler, yaşı yetişkinlerin ve ailelerinin değil, sağlık hizmeti sağlayıcılarının ihtiyaçlarını karşılayacak şekilde yapılandırılma eğilimindedir. İniş ve çıkışı riskli hale getiren yükseltilmiş yatak ve sedyeler, 1slak görünen soğuk ve parlak zeminler, bağımsızlığı zorlaştıran dar koridorlar, yönlendirmeyi destekleyecek uygun boyutta tabelaların bulunmaması, kişilerin kafasını karıştıran prosedürler buna verilebilecek örneklerdir (Parke B.,\& Stevenson L., 1999). Yaşlı dostu hastane ortamını oluşturmak için sermaye geliştirme ve fiziki altyapıda yer alan personelin, yaşlı dostu çevre tasarımı konusunda eğitimi ve kaynaklara erişimlerinin olması önemli bir noktadır (Wong K. et al., 2010). Yaşlılar için tasarlanmış bakım kalitesindeki iyileşmeyi ölçmek amacıyla yaşlı dostu göstergelerin oluşturulması önemlidir. Geriatrik bakımdaki sorunlar karmaşık müdahaleler gerektirir. Buradaki zorluk, tüm kuruluşların toplayabileceği anlamlı göstergeler tanımlamaktır (Wong K. et al., 2010). Geleceği tahmin etmenin en iyi yolu onu icat etmektir. Hastanelerimizde kültürel bir değişim yaratmak için insanların bakış açılarını

163 | P a g e

www.iiste.org 
ve paradigmalarını değiştirmek, gerontolojik gelişimsel bir bakış açısı içeren hastane bakımını öngörmek, sistemsel değişimi yaratarak nüfustaki 65 yaş ve üzeri bireylerin artış hızına ayak uydurabilen bir hizmet planlaması yapmak bir zaruriyettir.

\section{Kaynaklar}

[1] Accessible and Senior Friendly Hospital Plan (2014). August 2012 - December 2014,Muskoka Algonquin Healthcare. P:\A Senior Management Team\Accessibility $\backslash$ MAHC Accessibility Plan.doc

[2] Age Friendly Primary Health Care Centres Toolkit (2008). World Health Organization. Available: https://www.who.int/ageing/publications/AF_PHC_Centretoolkit.pdf (January 31, 2020)

[3] Age-Friendly Primary Health Care Centres Toolkit Trainer Guide for Normal Ageing and

Communication (2008). World Health Organization. Available: https://www.who.int/ageing /publications/AF_PHC_Centretoolkit.pdf (January 31, 2020)

[4] Ahmadi, A. et al. (2015). Towards Age-Friendly Hospitals in Developing Countries: A Case Study in Iran. Health Promotion Perspectives. Vol. 5, No. 1, P: 42-51

[5] Boeckxstaens P., \& Graaf PD.(2011). Primary care and care for older persons: Position Paper of the European Forum for Primary Care. 2011 European Forum for Primary Care. Quality in Primary Care.19:369-389

[6] Briefing: Health and Care of Older People in England 2019.1-70. (2019). Available: https://www.ageuk.org.uk/globalassets/age-uk (November 12, 2019)

[7] Fulmer T., \& Berman A. (2019). Age-Friendly Health Systems: How Do We Get There? [online]. Available: https://www.healthaffairs.org/do/10.1377/hblog20161103.057335/full/ (November 10, 2019)

[8] Fulmer T. et al. (2018). The Age-Friendly Health System Imperative. Journal of the American Geriatrics Society (JAGS) 66:22-24

[9] Hayat Tabloları, 2016- 2018 (2019). 24.09.2019 tarih, 30712 sayılı TÜİK Haber Bülteni. Available: www.tuik.gov.tr (October 15, 2019)

[10] Health PEI. One Island Health System. Senior Friendly Medical Unit. Available: www.princeedwardisland.ca (July 24, 2015)

[11] Kelley ML. Et al. (2011). Senior-friendly emergency department care: an environmental assessment. Journal of Health Services Research \& Policy Vol 16 No 1, 6-12

[12] Liu B. et al. (2010). Cal Martell and Martell Consulting. Background Document: Senior Friendly Care in Hamilton Niagara Haldimand Brant LHIN Hospitals, July

[13] Mate KS. et al. (2018). Creating Age-Friendly Health Systems - A vision for better care of older adults. Healthcare 6, 4-6

[14] Mimarlar Odası Ulaşılabilirlik Kılavuzu (Mimari Projelerde Engelli ve Yaşlılarla İlgili Olarak Uyulması Gereken Temel Kurallar), Available: http://www.izmimod.org.tr/yasa/engelli.html, (January 01, 2020)

[15] O'Keeffe J. (2018). Creating a Senior Friendly Physical Environment in our Hospitals. Available: https://www.rgptoronto.ca/wp-content/uploads/2018/12/creating-a-senior-friendlyphysical-environment-in-our-hospitals.pdf (December 16, 2019) 
[16] Parke B. (2007). Physical Design Dimension of an Elder Friendly Hospital: An evidence-based practice review undertaken for the Vancouver Island Health Authority

[17] Parke B., \& Friesen K. (2015). Code plus physical design components for an elder friendly hospital 2nd edition. Fraser Health

[18] Parke B.,\& Stevenson L. (1999). Creating an Elder-Friendly Hospital. Healthcare Management Forum. 12(3):45-48

[19] Sağlık Bakanlığı Sağlık Kurumlarında Engelli Bireyler İçin Ulaşılabilirlik Temel Bilgiler Rehberi.( 2012). Ankara. Available: www.saglik.gov.tr (January 12, 2020)

[20] Şahin S. (2008). İleri Yaş Dostu Hastane Projesi. İzmir 1. İleri Yaş Sempozyumu. 2021/Mart/2008

[21] Towards Age Friendly Primary Health Care. (2004) World Health Organization. Available: https://www.who.int/ageing/publications/phc/en/ ( January 15, 2020)

[22] Türkiye Sağlıklı Yaşlanma Eylem Planı ve Uygulama Programı 2015-2020 (TSYEPUP). (2015) Sağlık Bakanlı̆̆

[23] What Does It Mean to Be Age-Friendly? (2019). Available: http://www.ihi.org/AgeFriendly (October 25, 2019)

[24] www.who.int. Available: January 01, 2020

[25] Woo J. (2007). Development of elderly care services in Hong Kong: challenges and creative solutions. Clinical Medicine Vol 7 No 6, 548-550

[26] Woo J. et al. (2013). Age-Friendly Primary Health Care: An Assessment of Current service Provision for Older Adults in Hong Kong. Health Services Insights. 6, 69-77

[27] Wong K. et al. (2010). A Summary of Senior Friendly Care in Toronto Central LHIN Hospitals. Available: https://www.rgptoronto.ca/wpcontent/uploads/2018/03/SFH_Summary_of_CLHIN_2011.pdf (October 18, 2019)

[28] www.tuik.gov.tr. Available: February 04, 2020

\section{Ekler}

Ek 1. Yaşı Dostu Hastane Değerlendirme Kriterleri

\begin{tabular}{|l|l|}
\hline \multicolumn{2}{|c|}{ EK 1. YAŞLI DOSTU HASTANE DEĞERLENDİRME KRİTERLERİ } \\
\hline Standart No & \multicolumn{1}{c|}{ STANDART KONUSU } \\
\hline A & GENEL DÜZENLEMELER \\
\hline A.1 & Hastanenin Yaşlı Dostu Uygulamalarına yönelik bir politikası olmalıdır. \\
\hline A.2 & $\begin{array}{l}\text { Yaşlı Dostu Hastane Politikası iri punto yazıyla, uzaktan okunacak şekilde } \\
\text { hazırlanarak, hastanede herkesin görebileceği yerlere asılmalıdır. }\end{array}$ \\
\hline A.3 & Kurum politikada taahhüt ettiği kriterlerle ilgili tüm şartları yerine getirmelidir. \\
\hline A.4 & Hastanede Genel Yoğun Bakım Ünitesi bulunmalıdır. \\
\hline A.5 & Hastanede Palyatif Bakım Merkezi bulunmalıdır. \\
\hline A.6 & Hastanede Evde Sağlık Hizmetleri Birimi bulunmalıdır. \\
\hline
\end{tabular}




\begin{tabular}{|c|c|}
\hline A.7 & $\begin{array}{l}\text { Evde Sağlık Hizmetleri Birimi hastanenin hizmet bölgesinde bulunan diğer evde } \\
\text { sağlık / bakım hizmetleri birimi ile koordinasyon içinde olmalıdır.(Belediye, Özel, } \\
\text { Kamu vs.) }\end{array}$ \\
\hline A.8 & $\begin{array}{l}\text { Yaşı bireylerin talepleri halinde toplu taşıma araç noktalarına transferini } \\
\text { sağlayabilecek bir sistem / uygulama olmalıdır. (Bu konuda Yerel Yönetimlerle } \\
\text { işbirliği yapılmalıdır.) }\end{array}$ \\
\hline A.9 & $\begin{array}{l}\text { Yaşlı bireylerin yapılacak tedavi ve işlemler için onay ve bilgilendirmeleri alınırken } \\
\text { istekleri halinde imza edecekleri onam formu ve bilgilendirme dokümanlarının } \\
\text { kendilerine sesli olarak okunabileceği söylenmelidir. }\end{array}$ \\
\hline A.10 & $\begin{array}{l}\text { Hastane acil servisi içerisinde } 65 \text { yaş ve üzeri hastaların muayene ve tedavileri için } \\
\text { özel bir alan oluşturulmalıdır. }\end{array}$ \\
\hline A.11 & $\begin{array}{l}\text { Yoğun bakım içerisinde } 65 \text { yaş ve üzeri bireyler için kullanılacak olan yataklar } \\
\text { tanımlanmış olmalı, bu yataklar mümkün olduğunca hemşire bankolarına yakın } \\
\text { tasarlanmalıdır. }\end{array}$ \\
\hline A.12 & $\begin{array}{l}65 \text { yaş ve üzeri bireylere talepleri halinde hastanedeki tüm iş ve işlemleri boyunca } \\
\text { refakat desteği verilmeli, bu hizmetin sunulduğu ilan edilmiş olmalıdır. }\end{array}$ \\
\hline A.13 & $\begin{array}{l}\text { Hastanede } 65 \text { yaş ve üzeri bireylerin işlemlerini kolaylaştırıcı sistemler } \\
\text { bulunmalıdır. (Sesli destek sistemi, Karşılama Personeli, Host Hizmeti vs) }\end{array}$ \\
\hline A.14 & $\begin{array}{l}\text { Hastane bünyesinde "Fiziksel Egzersiz ve Aktif Yaşam Okulu" açılmalıdır. Bu } \\
\text { okulda } 65 \text { yaş ve üzeri bireyler öncelikli olmak üzere başvuranlara aktif ve sağlıklı } \\
\text { yaşam konusunda bilgilendirme ve egzersiz uygulamaları yaptırılmalıdır. } \\
\text { Başvuranlara bu hizmet Fizyoterapist veya eğitimli bir hemşire tarafından } \\
\text { verilebilir. }\end{array}$ \\
\hline A.15 & $\begin{array}{l}\text { Yaşı Dostu Hastane çalışmalarını düzenlemek, izlemek, değerlendirmek ve } \\
\text { periyodik olarak hastane yönetimine rapor etmek üzere bir komite kurulmalıdır. } \\
\text { Komitede multidisipliner yaklaşımla hastanede yaşlıya hizmet sunan tüm meslek } \\
\text { dallarından temsilci bulunmalıdır. Komite toplantıları kayıt altına alınmalıdır. }\end{array}$ \\
\hline A.16 & $\begin{array}{l}\text { Koruyucu hekimlik kapsamında kanser taramaları (serviks, meme, kolon, prostat } \\
\text { vb.), aşılama (influenza, pnömokok, tetanoz, hepatit vb.), periyodik muayene } \\
\text { (hipertansiyon, diabet, görme, işitme, hiperlipidemi vb.), beslenme, sigara ve alkol } \\
\text { kullanım alışkanlıklarının önlenmesi ve geriatrik değerlendirme gibi yaşlıya } \\
\text { verilecek hizmetlere ilişkin prosedür hazırlanmalıdır. }\end{array}$ \\
\hline A.17 & $\begin{array}{l}\text { Yaşlıya yönelik bakımın kalitesini ölçmek amacıyla düşme, basınç ülserleri, hastane } \\
\text { enfeksiyonları, malnutrisyon vb. konularda yaşlı dostu göstergeler oluşturulmalıdır. }\end{array}$ \\
\hline A.18 & $\begin{array}{l}\text { Yaşlıya sunulan hizmeti geliştirmek için anket, yüz yüze görüşme vb tekniklerle } \\
\text { görüşleri alınmalıdır. }\end{array}$ \\
\hline $\mathrm{B}$ & HASTANE İÇİ DÜZENLEMELER \\
\hline B.1 & KORİDORLAR ve HASTANE GİRİ̧̧LERİ \\
\hline B.1.1 & $\begin{array}{l}\text { Bina girişleri düzayak olmalı, varsa seviye farkı kabul edilebilir düzeyde olmalıdır.( } \\
\pm 0.6 \mathrm{~cm} \text { 'dir.) }\end{array}$ \\
\hline B.1.2 & Tüm bina girişleri iyi aydınlatılmış olmalıdır. \\
\hline B.1.3 & $\begin{array}{l}\text { Hastane girişlerini gösteren, uzaktan okunabilecek şekilde iri puntolarla yazılmış } \\
\text { yönlendirme tabelaları olmalıdır. }\end{array}$ \\
\hline B.1.4 & $\begin{array}{l}\text { Tüm hastane giriş kapıları tekerlekli sandalye vb. aparatlarla geçişe uygun olmalıdır. } \\
\text { ( Kapı genişliği en az } 100 \mathrm{~cm} \text {, kapı kanatlı bir kapı ise genişlik en az } 150 \mathrm{~cm} \\
\text { olmalıdır) }\end{array}$ \\
\hline B.1.5 & Giriş kapıları açılması fazla güç gerektirmeyen, kolay açılabilir olmalıdır. \\
\hline B.1.6 & $\begin{array}{l}\text { Bina girişi ve koridorlar yürüme güzergahında çöp kutusu, çiçeklik, tabela vb. } \\
\text { engeller olmamalıdır. }\end{array}$ \\
\hline B.1.7 & Bina girişinde rampa var ise eğimi \%6'dan az olmalıdır. \\
\hline B.1.8 & $\begin{array}{l}\text { Rampa en az bir tekerlekli sandalyenin geçebileceği genişlikte olmalıdır.( En az } 90 \\
\text { cm) }\end{array}$ \\
\hline B.1.9 & Rampanın başlama ve bitiş noktaları belirtilmiş olmalıdır. \\
\hline
\end{tabular}




\begin{tabular}{|c|c|}
\hline B.1.10 & $\begin{array}{l}\text { Rampa, merdivenler, sahanlıklar gibi bölümlerin duvar olmayan kısımlarında } \\
\text { yaşlıların yürüme esnasında denge kaybı vs nedenle düşmelerini önlemek için el ile } \\
\text { rahatça kavranabilecek genişlikte tutunma barı/ koruma bordürü olmalıdır. }\end{array}$ \\
\hline B.1.11 & $\begin{array}{l}\text { Hastaneye giriş kapıları ile asansör arası yürüme mesafesi yaşlıların yürümesine } \\
\text { uygun ve asgari düzeyde olmalıdır. }\end{array}$ \\
\hline B.1.12 & $\begin{array}{l}\text { Yürüme yerleri ve koridorlarda dinlenme ihtiyacı hissedecek yaşlılar için ergonomik } \\
\text { oturma alanları oluşturulmalıdır. }\end{array}$ \\
\hline B.1.13 & $\begin{array}{l}\text { Koridor ve yürüme alanlarında yol bulma işaretleri/çizgileri olmalı ve bunlar ipucu } \\
\text { niteliğinde işaret ve resimlerle desteklenmelidir. }\end{array}$ \\
\hline B.1.14 & Koridorlar kaygan olmayan malzemeden yapılmış olmalıdır. \\
\hline B.1.15 & $\begin{array}{l}\text { Koridorlarda bulunan yönlendirme tabelası vb. yaşlıların çarparak yaralanmalarının } \\
\text { önüne geçilmesi için baş seviyesi üzerinde olmalıdır. (Yerden en az } 220 \mathrm{~cm} \\
\text { yükseklikte) }\end{array}$ \\
\hline B.1.16 & $\begin{array}{l}\text { Acil çıkışlar kolay fark edilebilen 1şıklı yönlendirme işaretleri ve işitilebilir işaretler } \\
\text { şeklinde olmalıdır. }\end{array}$ \\
\hline B.1.17 & Tüm hastane içi ve koridorlar iyi aydınlatılmış olmalıdır. \\
\hline B. 2 & ASANSÖR ve MERDİVENLER \\
\hline B.2.1 & Hastanede mevcut tüm kat ve birimlere asansör ile ulaşılabilir olmalıdır. \\
\hline B.2.2 & Hastanenin her katına ulaşan asansörler birden fazla sayıda olmalıdır. \\
\hline B.2.3 & $\begin{array}{l}\text { Asansör kapısı tekerlekli sandalye vb. yürüme aparatlarının kolayca geçebileceği } \\
\text { genişlikte olmalıdır.( En az } 90 \mathrm{~cm} \text { ) }\end{array}$ \\
\hline B.2.4 & $\begin{array}{l}\text { Asansörler uzaktan rahatça görülebilecek şekilde dizayn edilmiş olmalıdır. (Duvarla } \\
\text { farklı/zit renkte vs.) }\end{array}$ \\
\hline B.2.5 & $\begin{array}{l}\text { Görme, okuma ve işitme sorunu olan yaşlıların da asansörü kullanabilmesi için } \\
\text { sesli, resimli, braille alfabesi ve normal yazı ile hazırlanmış kolay okunabilen } \\
\text { yardımcı araçlar olmalıdır. }\end{array}$ \\
\hline B.2.6 & Asansörler iyi aydınlatılmış olmalıdır. \\
\hline B.2.7 & $\begin{array}{l}\text { Asansör içinde tutunma barı bulunmalıdır. Tutunma barları elle kolay } \\
\text { kavranabilmeli ve farkedilmeyi kolaylaştırıcı renkte olmalıdır. }\end{array}$ \\
\hline B.2.8 & $\begin{array}{l}\text { Merdivenler kaymaz nitelikte malzeme ile yapılmış olmalı, tutunma yeri ve } \\
\text { korkulukları bulunmalıdır. }\end{array}$ \\
\hline B.2.9 & $\begin{array}{l}\text { Merdiven basamakları en fazla } 16 \mathrm{~cm} \text { yüksekliğinde, en az } 28 \mathrm{~cm} \text { genişliğinde, } \\
\text { uçları çıkıntısız olmalıdır. }\end{array}$ \\
\hline B.3 & KAPILAR \\
\hline B.3.1 & $\begin{array}{l}\text { Hastanede bulunan yaşlıların temas ettiği tüm alanlardaki kapılar yaşlıların } \\
\text { tekerlekli sandalye, walker benzeri yürüme aparatları ile rahatça geçebileceği } \\
\text { genişlikte olmalıdır. (Eni en az } 90 \mathrm{~cm} \text {, yüksekliği } 210 \mathrm{~cm} \text { olmalıdır.) }\end{array}$ \\
\hline B.3.2 & Hastane içerisinde bulunan tuvaletlerin kapıları dışa açılır olmalıdır. \\
\hline B.3.3 & $\begin{array}{l}\text { Hastanede mevcut her katta tekerlekli vb. aparat kullanan yaşlıların kullanımı için } \\
\text { engelli mevzuatlarına uygun hazırlanmış tuvalet bulunmalıdır. }\end{array}$ \\
\hline B.3.4 & $\begin{array}{l}\text { Hastanedeki kapılar fazla güç gerektirmeden kolay açılabilecek tarzda dizayn } \\
\text { edilmelidir. }\end{array}$ \\
\hline B.3.5 & $\begin{array}{l}\text { Kapı girişleri eşiksiz olmalı ve kapılar fark edilebilir şekilde duvardan farklı renkte } \\
\text { olmalıdır. }\end{array}$ \\
\hline B.4 & TUVALET ve BANYOLAR \\
\hline B.4.1 & $\begin{array}{l}\text { Her katta en az bir adet tekerlekli sandalye vb. aparatlarla kullanılabilecek Engelli } \\
\text { WC standartlarına uygun tuvalet bulunmalıdır. Bu tuvalette klozet yanı tutunma } \\
\text { barları olmalı, kapı genişliği en az } 90 \mathrm{~cm} \text {, içinde kullanılan aparat ile rahat hareket } \\
\text { etmeye uygun olmalıdır. }\end{array}$ \\
\hline B.4.2 & Tuvalet zeminleri kaygan olmamalı ve kapıları dışa açılmalıdır. \\
\hline
\end{tabular}




\begin{tabular}{|c|c|}
\hline B.4.3 & $\begin{array}{l}\text { Tuvalet içerisinde acil çağrı butonu bulunmalı ve bu farkedilebilir renk ve şekilde } \\
\text { olmalıdır. }\end{array}$ \\
\hline B.4.4 & Tuvalet muslukları kolay açılabilir nitelikte olmalıdır. \\
\hline B.4.5 & $\begin{array}{l}\text { Hasta odalarında bulunan banyolarda, banyo yapımı esnasındaki düşmeleri } \\
\text { engellemek amacıyla duvara monte edilmiş oturma aparatı ve tutunma barları } \\
\text { bulunmalıdır. }\end{array}$ \\
\hline B.4.6 & $\begin{array}{l}\text { Hastanede ayakta veya oturarak yıkanamayacak hastalar için dizayn edilmiş bir } \\
\text { banyo veya taşınabilir sedye banyo bulunmalıdır. }\end{array}$ \\
\hline B.4.7 & $\begin{array}{l}\text { Gerek ayakta banyo yapamayan hastaların transferi gerekse hareket kısıtı olan } \\
\text { hastalarda çarşaf vb. değişimi esnasında kullanılmak üzere lift/ kaldıraç sistemi } \\
\text { bulunmalıdır. }\end{array}$ \\
\hline B.5 & YÖNLENDİRME LEVHALARI ve BİLGİLENDİRMELER \\
\hline B.5.1 & $\begin{array}{l}\text { Kapı yanları veya duvara paralel monte edilmiş işaret ve levhalar gözle } \\
\text { okunabilecek hizada (yerden yüksekliği } 120-160 \mathrm{~cm} \text { arası) ve iri punto ile yazılmış } \\
\text { olmalıdır. }\end{array}$ \\
\hline B.5.2 & $\begin{array}{l}\text { Duvara dik dizayn edilmiş tabela ve levhaların yerden yüksekliği en az } 220 \mathrm{~cm} \\
\text { olmalıdır. }\end{array}$ \\
\hline B.5.3 & $\begin{array}{l}\text { Hastanede bulunan tüm bilgilendirme ve yönlendirme amaçlı hazırlanmış tabela ve } \\
\text { levhalar üzerindeki yazıların harf yüksekliği en az } 15 \mathrm{~mm} \text { olmalı ve görüş } \\
\text { mesafesine göre her bir metre için bu büyüklük } 20-30 \mathrm{~mm} \text { arttırılmalıdır. }\end{array}$ \\
\hline B.5.4 & Yazılar kolay okunabilmesi için bulunduğu zeminle zıt renklerde yazılmalıdır. \\
\hline B.5.5 & $\begin{array}{l}\text { Bilgilendirmeler kolay anlaşılabilen basit ifadelerle hazırlanmalıdır. Okuma yazması } \\
\text { olmayan bireyler için tabelalar resimlerle desteklenmelidir. }\end{array}$ \\
\hline B.5.6 & $\begin{array}{l}\text { Hastane içi yönlendirmeler yaşlı bireylerin ihtiyaç duydukları her bölüme kolayca } \\
\text { ulaşabilmesini sağlayacak şekilde dizayn edilmelidir. }\end{array}$ \\
\hline B.5.7 & $\begin{array}{l}\text { Hastane girişinde Görme engelli yaşlılar için Braille alfabesi ile hazırlanan genel } \\
\text { bilgilendirme panosu olmalıdır. }\end{array}$ \\
\hline B.5.8 & Merdiven, asansör, tuvalet ve özellikli alan yönlendirmeleri bulunmalıdır. \\
\hline B.6 & KLINIIKLER \\
\hline B.6.1 & Klinik koridorlarında tutunma barları bulunmalıdır. \\
\hline B.6.2 & $\begin{array}{l}65 \text { yaş ve üzeri için mümkün ise hemşire desklerine yakın odalar tanımlanmalı ve } \\
\text { bu odaların içine de tutunma barları yapılmalıdır. }\end{array}$ \\
\hline B.6.3 & $\begin{array}{l}65 \text { yaş ve üzeri için tanımlanmış hasta odalarında bulunan tuvalet ve banyoda } \\
\text { tutunma barları ve duvara sabitlenmiş banyo oturma aparatı bulunmalıdır. }\end{array}$ \\
\hline B.6.4 & $\begin{array}{l}\text { Yürüme sorunu yaşayan hastaların hareket etmesine yardımcı olmak amacıyla } \\
\text { hastanede walker, tekerlekli yürüteç, üçayaklı baston, koltuk değneği, kaldıraç } \\
\text { sistemi gibi ortopedik aparatlar bulunmalıdır. }\end{array}$ \\
\hline B.6.5 & $\begin{array}{l}65 \text { yaş ve üzeri bireyler için tanımlanmış hasta odalarında bulunan telefonların } \\
\text { üzerindeki rakamlar büyük olmalıdır. }\end{array}$ \\
\hline B.6.6 & $\begin{array}{l}\text { Hasta odalarında bulunan telefonlarda hastaların acil ihtiyaç halinde ulaşacakları } \\
\text { dahili numaralar belirtilmiş olmalıdır. }\end{array}$ \\
\hline B.6.7 & $\begin{array}{l}\text { Hastanede yatarak tedavi gören } 65 \text { yaş ve üzeri hastalara ihtiyaçları halinde kurum } \\
\text { tarafindan refakatçi temin edilmelidir. }\end{array}$ \\
\hline $\mathrm{C}$ & EĞİTìM \\
\hline C. 1 & YAŞLI ve YAKINLARININ EĞİTiMİ \\
\hline C. 1.1 & $\begin{array}{l}\text { Yaşlılar ve yakınlarının ileri yaş döneminde sık karşılaşılan hastalıklarla ilgili } \\
\text { bilgilendirilmeleri amacıyla broşürler hazırlanmalıdır. }\end{array}$ \\
\hline C.1.2 & $\begin{array}{l}\text { Broşürler basit bir dille yazılmalı, çok yazıdan ziyade görsellerle desteklenmiş } \\
\text { bilgilendirme araçları olmalıdır. }\end{array}$ \\
\hline C.1.3 & $\begin{array}{l}\text { Hasta ve yakınları için hazırlanmış aktif yaşlanma için bilgilendirme ve egzesiz } \\
\text { broşürleri bulunmalıdır. }\end{array}$ \\
\hline C.1.3.1 & Yaşlilarda Fiziksel Aktivite ve Egzersiz \\
\hline
\end{tabular}


International Journal of Scientific and Technological Research

\begin{tabular}{|c|c|}
\hline C.1.3.2 & Alzheimer ve Egzersiz \\
\hline C.1.3.3 & KOAH ve Egzersiz \\
\hline C.1.3.4 & Diyabet ve Egzersiz \\
\hline C.1.3.5 & Yaşlılık ve Hipertansiyon \\
\hline C.1.3.6 & Yaşlılık ve Diyabet \\
\hline C.1.3.7 & Yaşlilık ve Osteoporoz \\
\hline C.1.3.8 & Yaşlılıkta Kronik Ağrı \\
\hline C.1.3.9 & Yaşlilik ve İnkontinans \\
\hline C.1.3.10 & Yaşl1lıkta Çoklu İlaç Kullanımı \\
\hline C.1.3.11 & Yaşlilikta Beslenme \\
\hline C. 2 & PERSONEL EĞİTİMİ \\
\hline C.2.1 & $\begin{array}{l}\text { Hastanede bulunan personellere hizmet alanlarına göre, yaşlı hastalara yaklaşım } \\
\text { konusunda farkındalık eğitimleri verilmelidir. }\end{array}$ \\
\hline C.2.2 & $\begin{array}{l}\text { Yaşlı Dostu Hastane kapsamında verilen bu eğitimler hastane oryantasyon } \\
\text { eğitimleri içine dahil edilerek, kuruma başlayan her yeni personelin bu eğitimleri } \\
\text { alması sağlanmalıdır. }\end{array}$ \\
\hline C. 2.3 & Eğitimler asgari aşağıda sayılmış konuları kapsamalıdır. \\
\hline C.2.3.1 & Yaşlilıkla İlgili Genel Bilgiler \\
\hline C.2.3.2 & Kırılgan Yaşlı \\
\hline C.2.3.3 & Geriatrik Sendromlar \\
\hline C.2.3.4 & Sağlıklı Beslenme \\
\hline C.2.3.5 & Kronik Hastalıklarda Beslenme \\
\hline C.2.3.6 & Demansta Beslenme \\
\hline C.2.3.7 & Demans ve Alzheimerli Hastaya Yaklaşım \\
\hline C.2.3.8 & Bakıcı Tükenmişliği ve Çözüm Önerileri \\
\hline C.2.3.9 & Yaşlı İle İletişim Yolları ve Bariyerler \\
\hline C.2.3.10 & İyi/Onurlu Ölüm \\
\hline C.2.3.11 & Palyatif Bakım Genel Bilgiler \\
\hline C.2.3.12 & Palyatif Bakıma Alınma ve Çıkarılma Kriterleri \\
\hline C.2.3.13 & Yaşlı Hakları \\
\hline C.2.3.14 & Yaşlı Ayrımcılığı, Yaşlı İhmal ve Suistimali \\
\hline C.2.3.15 & Nazogastik ve Peg Bakımı \\
\hline C.2.3.16 & Basınç Ülserleri \\
\hline C.2.3.17 & İnkontinans Alakalı Dermatit \\
\hline C.2.3.18 & Kolostomi ve Hemşirelik Bakımı \\
\hline C.2.3.19 & Yara Bakım Ürünleri \\
\hline C.2.3.20 & Yatak Başı Hasta Bakımı \\
\hline C.2.3.21 & Yaşl1lıkta Mobilite ve Egzersiz \\
\hline C.2.3.22 & Ağrı ile Baş Etme \\
\hline C.2.3.23 & Yaşlılıkta Aktivite Okulu \\
\hline C.2.3.24 & Yaşlı Dostu Hastane Kavramı \\
\hline C.2.3.25 & Yaşlı Dostu Hastane Kriterleri \\
\hline C.2.3.26 & İletişim Becerileri \\
\hline C.2.3.27 & Etkili Sunum Hazırlama ve Sunum Yapma \\
\hline
\end{tabular}


\begin{tabular}{l|l} 
C.3 & Hastanenin bulunduğu yerleşim yerinde bulunan diğer sağlık kurumlarında da
\end{tabular} "Yaşlı Dostu Hastane" konusunda farkındalık oluşturmak üzere bilgilendirme toplantıları yapılmalıdir.

Ek 2. Yaşlı Dostu Hastane Politikası

Ek 3. HASTANESİ YAŞLI DOSTU HASTANE POLİTİKASI

$\mathrm{Bu}$ Hastane;

- 65 yaş ve üzeri hastalara saygılı, onların ihtiyaçlarına yanıt verecek tarzda düzenlenmiş, zamanında ve kolay ulaşılabilir, ileri yaşa öncelik tanıyan hizmet sunumunu,

- Yaşlılara yönelik birincil sağlık hizmetleri hakkındaki farkındalığı arttırmayı,

- Fiziksel Egzersiz ve Aktif Yaşam Okulunda düzenli olarak sağlıklı yaşlanma ile ilgili eğitim ve uygulama hizmeti vermeyi,

- Hastaneye başvuran tüm hastaların yanı sıra 65 yaş ve üzeri bireylerin memnuniyetini arttırmayı önemsemeyi,

- Yatağa bağımlı ve refakatçisi olmayan hastalarda destek personeli sağlamayı,

- Hasta bakımında yer alan tüm personelin 65 yaş ve üzeri hastaların fiziksel ve duygusal ihtiyaçlarına yönelik bilgi ve becerilerini sürekli geliştirmeyi,

- Bakım alanlarında nitelikli personel çalıştırmayı ve personelin eğitimini teşvik ederek, yüksek farkındalık oluşturmayı, sürekli eğitim modeliyle tüm personeli 65 yaş ve üzeri bireylere yaklaşım konusunda duyarlı kılmayı,

- Güncel tıbbi teknolojik gelişmeleri zamanında eksiksiz uygulamayı, teknolojik desteği tüm alanlara ulaştırmayı ve sosyal sorumluluklarının bilincinde topluma en üst düzeyde katkı vermeyi,

- 65 yaş ve üzeri bireylerin özerkliğine saygı yaklaşımı ile kendilerine uygulanacak tüm tedavi ve girişimler konusunda bilgilendirilmesi ve rızalarının alınmasını,

- 65 yaş ve üzeri bireylerin istismar ve ihmalinin önlenmesi ve çalışanlar tarafından fark edilerek ilgili makamlara duyurulması konusunda sağlık personelini eğitmeyi,

- Yaş ayrımcılığı yapmamayı,

- Hastane fiziksel altyapısını ileri yaşa yönelik olarak düzenlemeyi,

- Hizmet verilen tüm alanlarda temiz ve güvenilir ortam sağlamayı,

- Hastanedeki diğer kalite ve acil durum politikalarında ileri yaşa yer vermeyi,

- Dost Yönetim Tarzı İle Kanıta Dayalı Medikal Bakımın Verildiği, Dost Sağlık Personeli ve Dost Fiziksel Yapıya Sahip Hastane oluşturmayı,

Yaşlı Dostu Hastane Politikası olarak belirlemiştir. 